\title{
2018 Editor's Choice Award and Editor's Choice Articles
}

\author{
Kensuke Nakata ${ }^{1}$ \\ (c) Japan Ethological Society 2019
}

The editorial committee of the Journal of Ethology awards a prize for the best paper published in the journal, the Editor's Choice Award, every year. In addition the committee selects 6-10 papers as Editor's Choice articles. I am very pleased to announce the award winner and the list of the Editor's Choice articles for 2018 .

\section{Editor's Choice Award}

Tamako Miyazaki, Takashi Nishimura, Tetsuro Yamashita, and Masao Miyazaki (2018) Olfactory discrimination of anal sac secretions in the domestic cat and the chemical profiles of the volatile compounds (Vol. 36, Issue 1, pp 99-105)

The authors elucidate the function of anal sac secretions as chemical signals in domestic cats. The editorial committee considered the paper quite fascinating, since the study reveals the hidden chemical communication among cats, a very familiar animal to us that we may assume we already know much about. The committee also cited the robustness of the study method employed.

\section{Editor's Choice Articles}

Pre-ovipositional maternal care alleviates food stress of offspring in the flower beetle Dicronocephalus wallichii. By Wataru Kojima, Chung-Ping Lin (Vol. 36, Issue 2, pp 135-141)

Responses to relaxed and reverse selection in strains artificially selected for duration of death-feigning behavior in the red flour beetle, Tribolium castaneum. By Kentarou Matsumura, Takahisa Miyatake (Vol. 36, Issue 2, pp 161-168)

Kensuke Nakata

nakatake@kyoto-wu.ac.jp

1 Kyoto Women's University, Kyoto, Japan
Comparison of personality between juveniles and adults in clonal gecko species. By Osamu Sakai (Vol. 36, Issue 3, pp 221-228)

Effect of social condition on behavioral development during early adult phase in Drosophila prolongata. By Takashi Matsuo (Vol. 36, Issue 1, pp 15-22)

Influence of aging on brain and web characteristics of an orb web spider. By Alain Pasquet, Camille Toscani, Mylène Anotaux (Vol. 36, Issue 1, pp 85-91)

Mating and aggressive behaviour of Brachyrhaphis olomina (Cyprinodontiformes: Poeciliidae). By Carlos A. GaritaAlvarado, Beatriz Naranjo-Elizondo, Gilbert Barrantes (Vol. 36 , Issue 1, pp 1-13)

Ethological description of a fixed action pattern in a kissing bug (Triatominae): vision, gustation, proboscis extension and drinking of water and guava. By Oscar Páez-Rondón, Elis Aldana, Joseph Dickens, Fernando Otálora-Luna (Vol. 36, Issue 2, pp 107-116)

\section{Open Access}

These papers have now been made open access by the support from the Japan Ethological Society funded by JSPS KAKENHI Grant Number 18HP2005. I hope these papers will be read by many colleagues and will contribute to the future study of animal behaviour.

\section{References}

Garita-Alvarado CA, Naranjo-Elizondo B, Barrantes G (2018) Mating and aggressive behaviour of Brachyrhaphis olomina (Cyprinodontiformes: Poeciliidae). J Ethol 36:1-13 
Kojima W, Lin CP (2018) Pre-ovipositional maternal care alleviates food stress of offspring in the flower beetle Dicronocephalus wallichii. J Ethol 36:135-141

Matsumura K, Miyatake T (2018) Responses to relaxed and reverse selection in strains artificially selected for duration of deathfeigning behavior in the red flour beetle, Tribolium castaneum. J Ethol 36:161-168

Matsuo T (2018) Effect of social condition on behavioral development during early adult phase in Drosophila prolongata. J Ethol $36: 15-22$

Miyazaki T, Nishimura T, Yamashita T et al (2018) Olfactory discrimination of anal sac secretions in the domestic cat and the chemical profiles of the volatile compounds. J Ethol 36:99-105

Páez-Rondón O, Aldana E, Dickens J et al (2018) Ethological description of a fixed action pattern in a kissing bug (Triatominae): vision, gustation, proboscis extension and drinking of water and guava. J Ethol 36:107-116

Pasquet A, Toscani C, Anotaux M (2018) Influence of aging on brain and web characteristics of an orb web spider. J Ethol 36:85-91

Sakai O (2018) Comparison of personality between juveniles and adults in clonal gecko species. J Ethol 36:221-228

Publisher's Note Springer Nature remains neutral with regard to jurisdictional claims in published maps and institutional affiliations. 